\title{
ICE-SHEET FAILURE AGAINST INCLINED AND CONICAL SURFACES
}

\author{
MOVSES J. KALDJIAN \\ Department of Naval Architecture and Marine Engineering, \\ The University of Michigan, Ann Arbor, MI 48109, U.S.A.
}

\begin{abstract}
Ice-sheet/structure interation models were prepared and analyzed numerically. The study covers parameters to analyze displacement boundaries, the effects of sharp forward ridges, artificially induced cracks, etc. These variables are difficult and costly to incorporate into experimental work.

The floating ice-sheet was studied as a large, rectangular, continuous plate supported by springs (equivalent buoyancy). The plate was beld at the far edge and a displacement boundary condition applied at the middle of the near edge. The displacement condition is that of the contact surface edge geometry of an offshore or ship structure.

The models were analyzed using finite element techniques. Nonlinear material property and geometry effects were also considered. The resulting force, stress and displacement patterns indicate that a modified geometry of structure will produce smaller forces to break up the ice, especially when coupled with radial precuts in strategic locations. Results show good agreement with the experimental data obtained by Frederking and Timco (Proc. 4th International Offshore Mechanics and Arctic Engineering Symposium, ASME, Dallas, pp. 160-169, 1985). The analytical expressions available to predict floating ice loads on structures can be verified and re-evaluated by extending present work.
\end{abstract}

\section{INTRODUCTION AND BACKGROUND}

The present national oil glut notwithstanding, more and more offshore structures are being planned and constructed. Many of these are slated for cold regions, like the Beaufort Sea, where the menacing presence of floating ice poses a seasonal hazard to these structures, as well as to the transport ships that play an essential role in their operation and maintenance.

Offshore structures and the ships that service them have to be designed to withstand the forces produced by the floating ice cover as it presses against the structure, crushes, breaks and drifts away. This scenario is repeated intermittently at various lengths, depending on the severity of the winter.

The interaction between the ice cover and a structure is very complex. Many forces are at play at a given moment, crushing and flexural failure, translation and rotation of the ice pieces, buoyancy, gravity and ice friction to lift, move and slide the broken ice pieces around the structure.

A number of investigators [1-6] have studied analytically the problem of ice forces on inclined structures. All, except [3], treat ice as an elastic/brittle material, and as either a two-dimensional or threedimensional problem [1].

Other investigators $[1,5,7]$ have studied the same ice forces on inclined plane structures experimentally through small scale models, and discovered that analytical results consistently underpredict ice/structure interaction forces, and have suggested revisions to the analytical expressions previously proposed.

An economic and safe structural design requires a thorough quantitative understanding of the loads involved in the ice/structure interaction. Frederling and Timco [1] report that in ice/structure inter- action the maximum breaking load was associated with the formation of radial cracks in the ice-sheet in front of the inclined plane, rather than circumferential cracks as shown in Fig. 1.

Further experiments with built-in cracks conclusively verified their observation. The presence of built-in circumferential cracks was insignificant, while the built-in radial cracks reduced the maximum breaking load by half as shown in Fig. 2 . Work at the University of Michigan using finite element analysis with and without built-in cracks showed good agreement with the experimental data obtained by Frederling and Timco [1].

Thus, through numerical analysis, we can calcu-
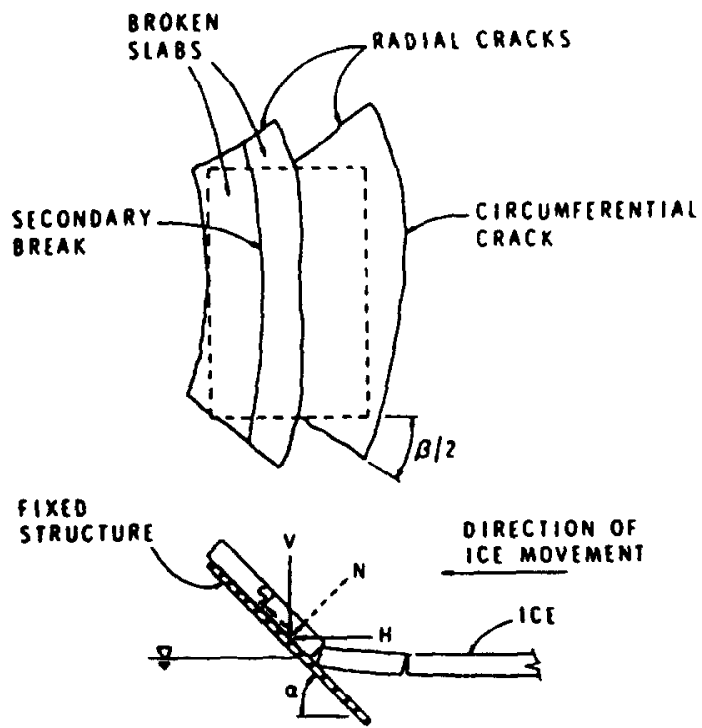

Fig. 1. Schematic of ice behavior on an inclined plane structure. 

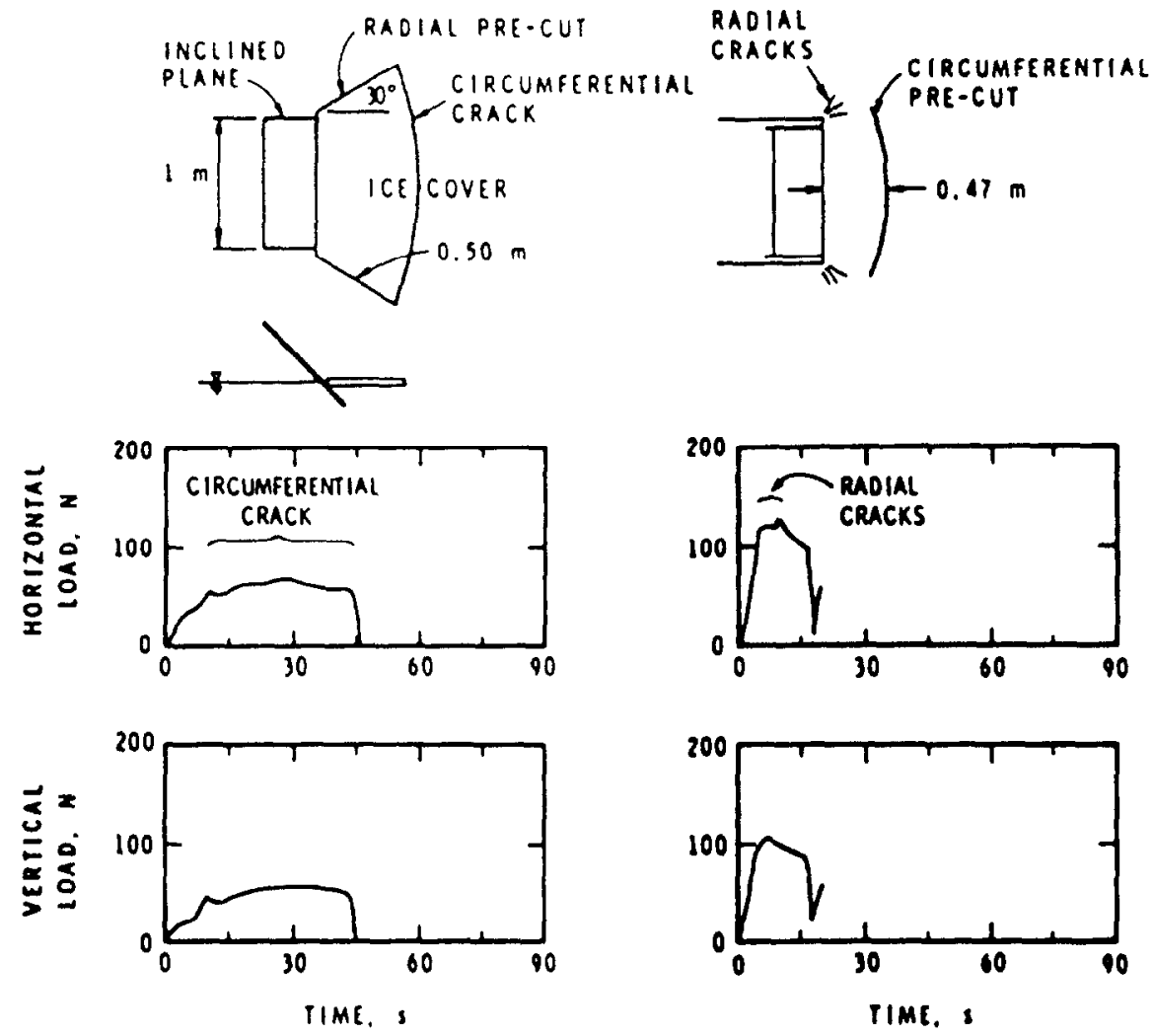

a) RADIAL PRE-CUTS

O) CIRCUMFERENTIAL PRE-CUTS

Fig. 2. Model test results for a 45-degree upward-breaking inclined plane.

late the location of maximum flexural stress in the ice-sheet. Firing high pressure hot water jets to these spots (or possibly building sharp ridges forward of the structure at these points), or using a mechanical device similar to Ditch Witch machine as done by Manikian et al. [8], will precipitate formation of radial cracks and thereby reduce the value of the maximum breaking load that an offshore structure has to withstand without causing environmental side effects.

This numerical study presents in part the effects of the following parameters, namely offshore structure geometries (i.e. the siopes and sizes of inclined planes and conical surfaces, displacement boundaries, sharp forward ridges), friction, geometric and material nonlinearity, and artificially induced cracks on the ice/ offshore structure load interactions.

\section{PROBLEM DEFINITION AND NUMERICAL APPROACH}

Experimentally obtained data on ice/structure interaction loads are few in number and costly to obtain. To extend this data bank, mathematical models were prepared and analyzed numerically. The study covered loads and displacement boundaries to accommodate inclined planes, conical sur-

Table 1

\begin{tabular}{lcccccc}
\hline $\begin{array}{c}\text { Model } \\
\text { No. }\end{array}$ & $\mathrm{A}_{Y}$ & $\mathrm{~A}_{\mathbf{z}}$ & $\mathrm{B}_{\boldsymbol{r}}$ & $\mathrm{B}_{\mathbf{z}}$ & $\mathrm{C}_{\boldsymbol{r}}$ & $\mathrm{C}_{\mathbf{z}}$ \\
\hline I.1 & -0.19 & 91.1 & -0.18 & 87.2 & -0.15 & 76.7 \\
I.2 & -0.46 & 99.2 & -0.41 & 94.6 & -0.29 & 82.4 \\
I.3 & -0.20 & 112.5 & -0.19 & 109.3 & -0.17 & 100.5 \\
II.1 & $(-5)$ & $(100)$ & -2.64 & 95.54 & -2.06 & 80.35 \\
II.1C & $(-5)$ & $(100)$ & -2.10 & 89.52 & -1.58 & 75.16 \\
II.2 & -4.33 & 104.3 & $(-5)$ & $(100)$ & -3.46 & 86.79 \\
II.2C & -4.70 & 108.7 & $(-5)$ & $(100)$ & -3.29 & 85.00 \\
II.2CG & -9.68 & 217.8 & $(-10)$ & $(200)$ & -6.71 & 168.91 \\
II.2CN & -8.77 & 217.2 & $(-10)$ & $(200)$ & -4.87 & 159.87 \\
I1.5 & $(-5)$ & $(100)$ & $(-4)$ & $(80)$ & $(-1.5)$ & $(30)$ \\
II.5F & -0.20 & 89.2 & -0.18 & 85.52 & -0.16 & 74.93 \\
\hline
\end{tabular}

( ) = specified displacement. 


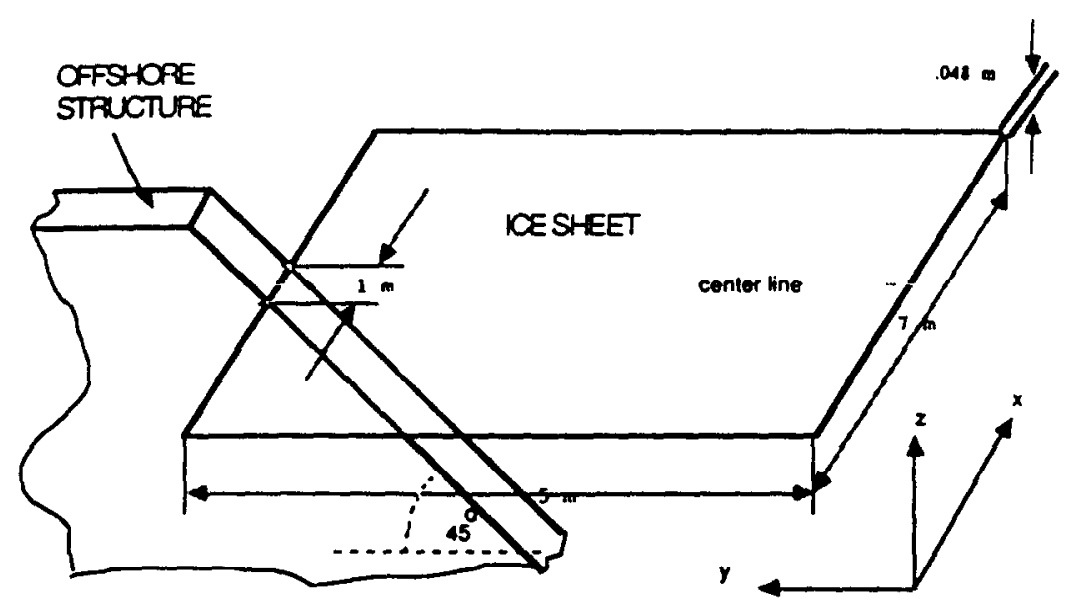

Fig. 3. Ice cover and the inclined plane structure.

faces, sharp forward ridge effects, and mechanically induced pre-cracks. These variables are difficult and costly to incorporate into experimental work, yet important and essential in preparing better analytical expressions for predicting ice/structure interaction loads.

As a slow moving, floating ice-sheet encounters an offshore structure, interaction loads throughout the contact area cause stress field build-up in the icesheet. When these stresses are high enough, the icesheet cracks, breaks, and causes the ice-sheet to advance. This process is repeated many times. Our goal was to develop a numerical tool to predict the value of the interactive load that causes the ice to break, and establish ways to reduce its magnitude. Mathematical models of the floating ice-sheet as a large, rectangular, continuous plate supported by springs (equivalent buoyancy) were prepared. The plate was held at the far edge and a displacement boundary condition of an inclined plane or conical surface applied statically at the middle of the near edge. The displacement boundary condition was that of the contact surface edge geometry of the offshore, or ship structure.

The mathematical modeis were analyzed using finite element techniques which are well suited for boundary displacement loads. This way nonlinear property and geometry effects can also be evaluated as desired. The resulting stress and displacement fields are presented graphically in this paper.

\section{FINTTE ELEMENT MODELS}

Two different finite element programs were utilized to perform the analysis of the ice/structure interaction.

For Series I models, the Michigan Structural Analysis Program (MSAP) was used. It is based on SAP IV [9] and is a linear program.

For Series II models, the program ADINA was used. This is a nonlinear finite element program developed by Bathe at Massachusetts Institute of

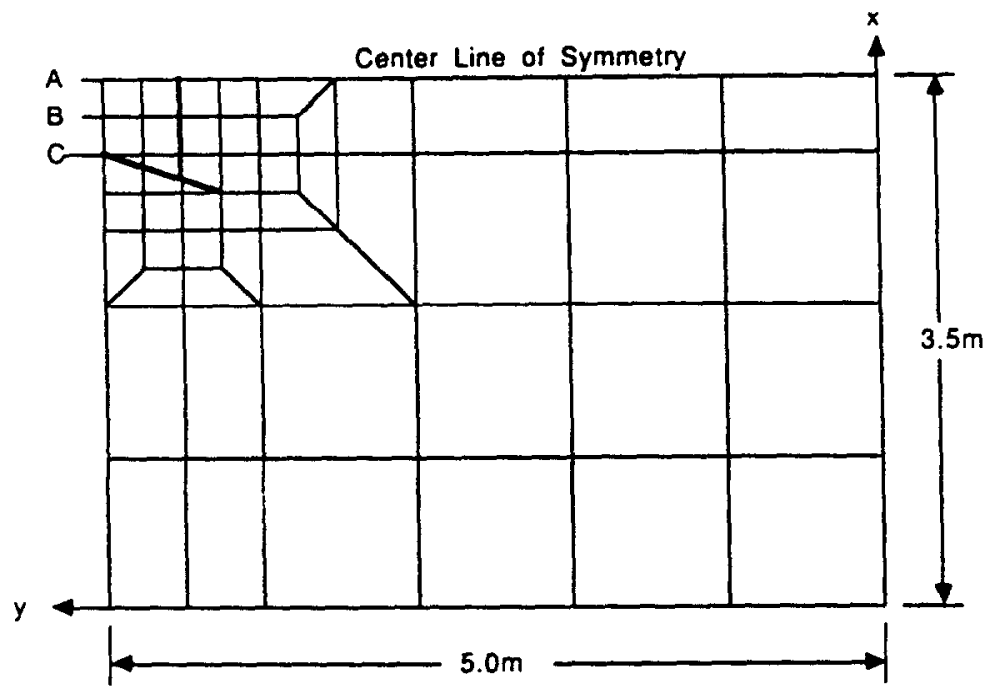

Fig. 4. Finite element model of the ice cover, for MSAP Series I. 


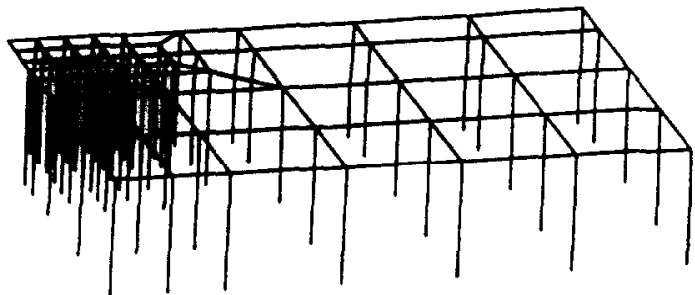

Fig. 5. Finite element model of ice cover pressing on an incline plane showing buoyancy elements, Series I.

Technology [10]. In the present study, except for two models, II.2CG and II.2CN, ADINA was used mostly in the linear mode but we plan to study this ice/structure interaction further nonlinearly. Also, it was of interest to obtain solutions to the same problem using different types of elements and compare the results. Table 1 models I.1 and II.SF show excellent agreement.

Experimental work of Frederking and Timco [1] formed the basis of the mathematical model of our numerical study. The ice sheet was $7 \mathrm{~m}$ wide, $5 \mathrm{~m}$ long and $0.048 \mathrm{~m}$ thick, as seen in Fig. 3, with an elastic modulus of $240 \mathrm{MPa}$ and Poisson's ratio of 0.333 .

Because of symmetry the finite element (FE) models needed to be half as large. The FE model discretization are shown presented in Figs 4 and 9. The ice sheet was treated as supported by elastic foundation. The buoyancy produced by the water is lumped at the nodal points using truss (line) elements and is sho'vn in Figs 5-8.

Series I model: This was for MSAP and had a total of 140 nodal points, 52 plate/shell elements and 60 truss elements.

Series II model: This was for ADINA and had a total of 236 nodal points, 28 multi N.P. 3/D shell elements and 88 truss elements.

\section{Series I}

Plate elements with springs were used to model the ice/buoyancy effects with the finite element program MSAP. It was force-loaded uniformly on the edge in contact with the inclined plane. The equivalent concentrated applied loads are as follows.

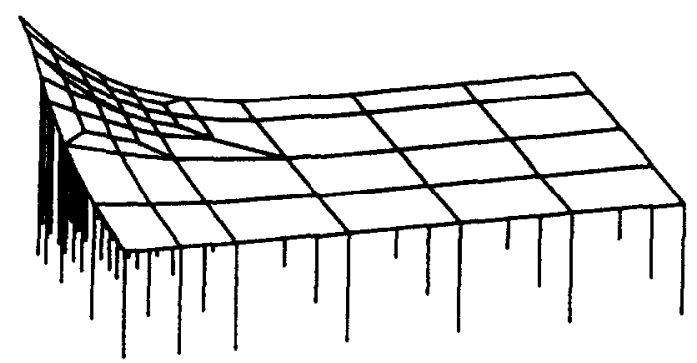

Fig. 6. Deformation in ice cover due to forces from an incline plane without precracks (I.1).

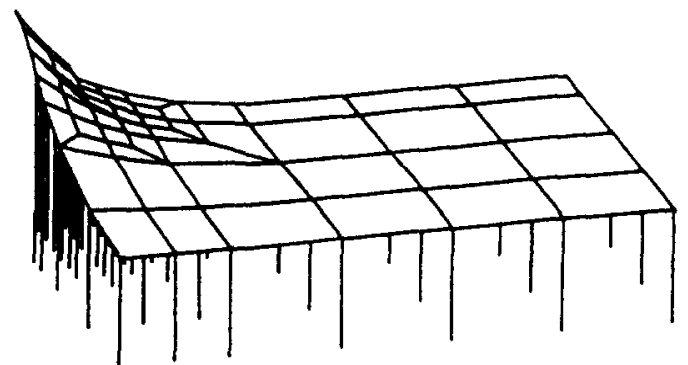

Fig. 7. Deformation in ice cover due to forces from an incline plane with precracks-circumferential (1.2).

\begin{tabular}{ccc}
\hline Nodal point & $\begin{array}{c}\text { Force }-Y \\
(\mathrm{kN})\end{array}$ & $\begin{array}{c}\text { Force }-Z \\
(\mathrm{kN})\end{array}$ \\
\hline A & -0.01475 & 0.0125 \\
B & -0.0245 & 0.0250 \\
C & -0.01475 & 0.0125 \\
\hline
\end{tabular}

Figure 4 shows the nodal point locations of these points.

The following three models were studied for the above load condition:

I.1 Ice sheet with no precuts.

I.2 With circumferential precut.

1.3 With radial precut.

The dark lines in Fig. 4 represent the precut positions.

\section{Series II}

Here multi-nodal $3 / D$ shell elements with springs were used to model the ice/buoyancy effects with the finite element program ADINA, in linear and nonlinear modes.

This series was mostly displacement loaded at edge of contact, which is considered to be more realistic than the edge force load condition of Series I.

The following eight models were studied in this series:

II.1 Displacement at nodal point A only.

II.1C Displacement at $A$ with radial precut at center line of symmetry.

II.2 Displacement at B.

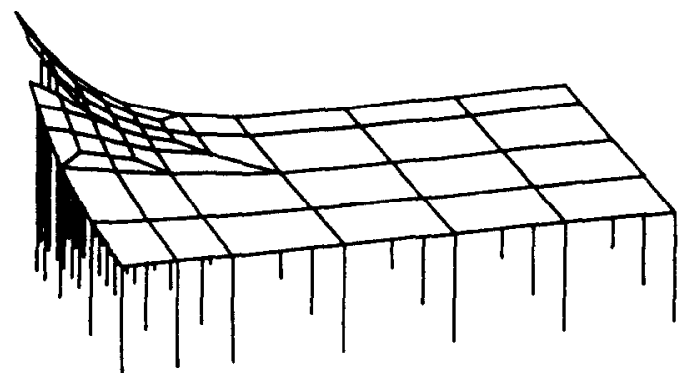

Fig. 8. Deformation in ice cover forces due to forces from an incline plane with precracks-radial (1.3). 


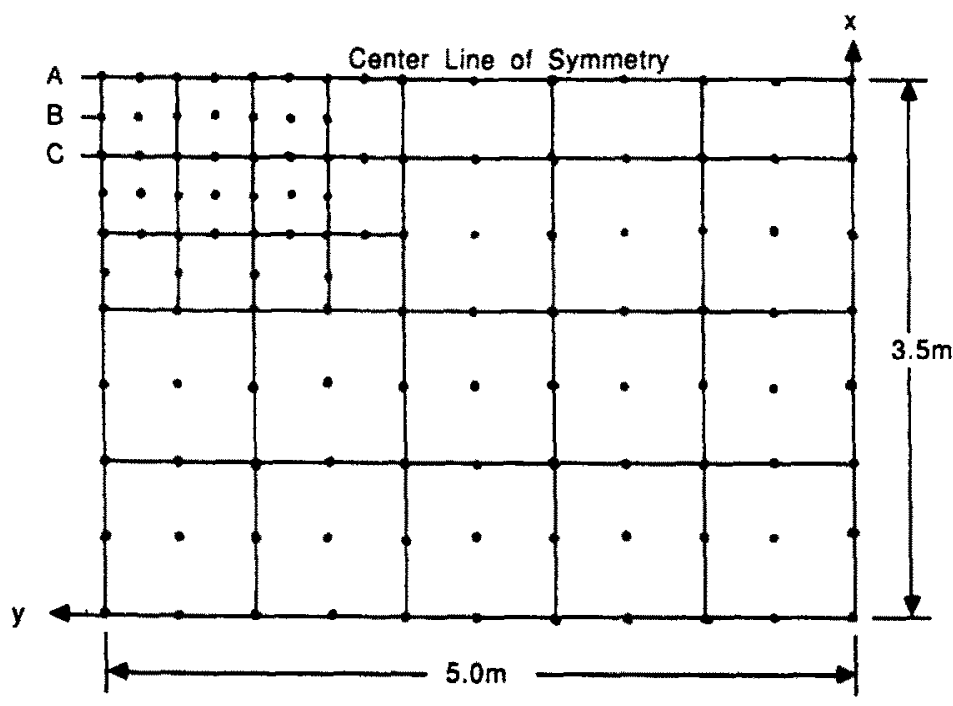

Fig. 9. Finite element model of the ice cover for ADINA Series 11.
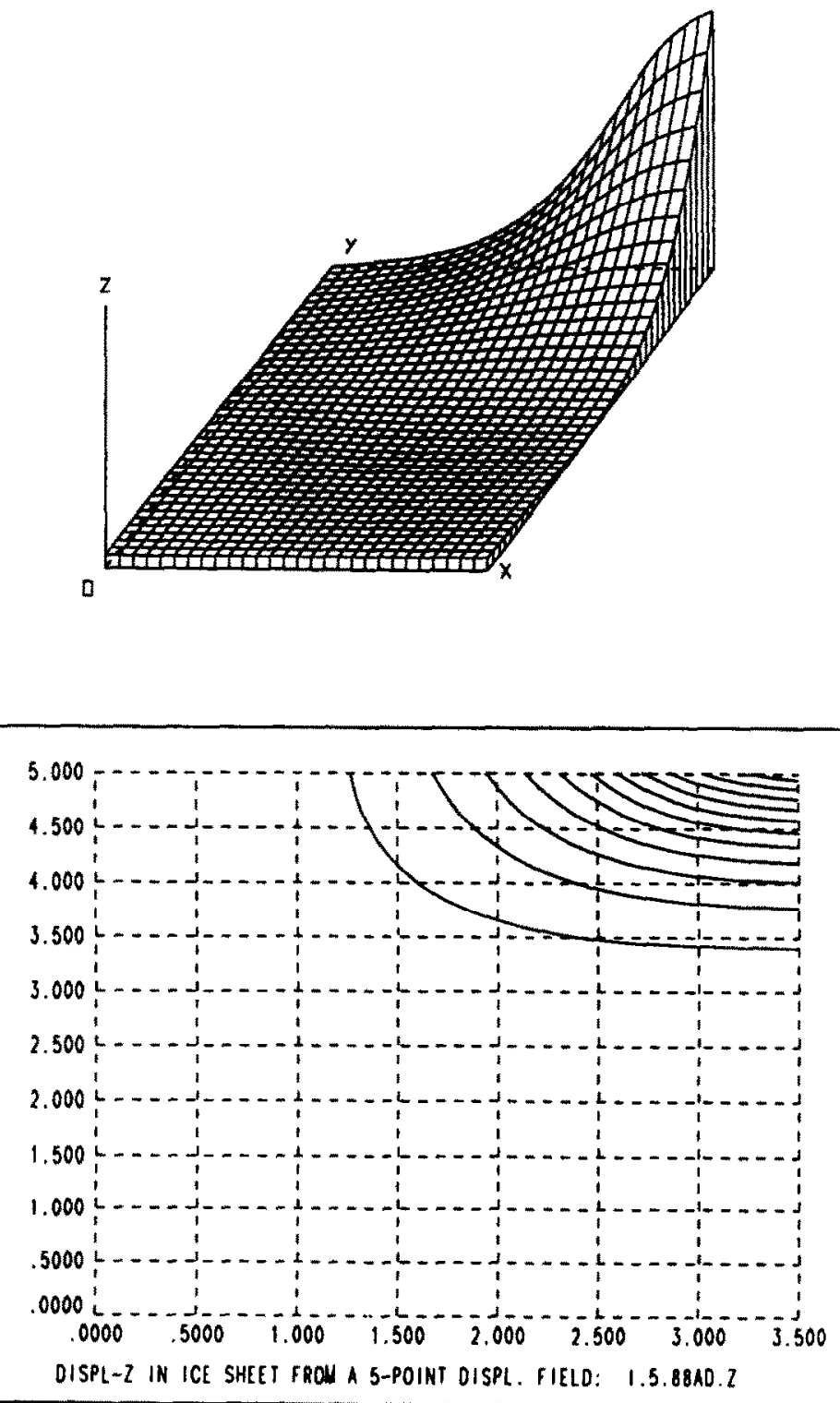

Fig. 10. Z-displacement in contour and in relief (II.S). 
Table 2

\begin{tabular}{|c|c|c|c|c|c|c|}
\hline \multirow{2}{*}{$\begin{array}{c}\text { Model } \\
\text { No. }\end{array}$} & \multirow[b]{2}{*}{$A_{\gamma}$} & \multicolumn{4}{|c|}{ Displacement $\times 10^{-1} \mathrm{~m}$} & \multirow[b]{2}{*}{$\mathrm{C}_{2}$} \\
\hline & & $A_{2}$ & $\mathbf{B}_{\mathbf{Y}}$ & $\mathbf{B}_{\boldsymbol{z}}$ & $\mathrm{C}_{Y}$ & \\
\hline II. & -5 & 100 & & & & \\
\hline II.1C & -5 & 100 & & & & \\
\hline II. 2 & & & -5 & 100 & & \\
\hline $11.2 \mathrm{C}$ & & & -5 & 100 & & \\
\hline II. $2 \mathrm{CG}$ & & & -10 & 200 & & \\
\hline $11.2 \mathrm{CN}$ & & & -10 & 200 & & \\
\hline 11.5 & -5 & 100 & -4 & 80 & 1.5 & 30 \\
\hline II.SF & & (Force & undar & ame a & in I.1) & \\
\hline
\end{tabular}

$C=$ with precut on center line at $A$, see Fig. 4 .

II.2C Displacement at B with radial precut at center line of symmetry.

II.2CG Same as II.2C, plus nonlinear geometry.

II. $2 \mathrm{CN}$ Same as II.2CG, plus nonlinear material $\left(\sigma_{y}=100 \mathrm{kPa}, E_{r}=0\right)$.

II.5 Displacement at A, B and C.
II.5F Force loaded same as model I.1, for comparison purposes.

The nodal point locations of the specified displacement are shown in Fig. 9. The displacement values used for boundary condition in this series are shown listed in Table 2.

\section{RESULTS AND OBSERVATIONS}

The displacement results specified and calculated for all cases considered are shown listed in Table 1.

The following general observations can be made from this study.

1. Most of the upper surface of the ice sheet is subjected to compression and lower surface to tension.

2. Near the vicinity of the offshore structure, flexural
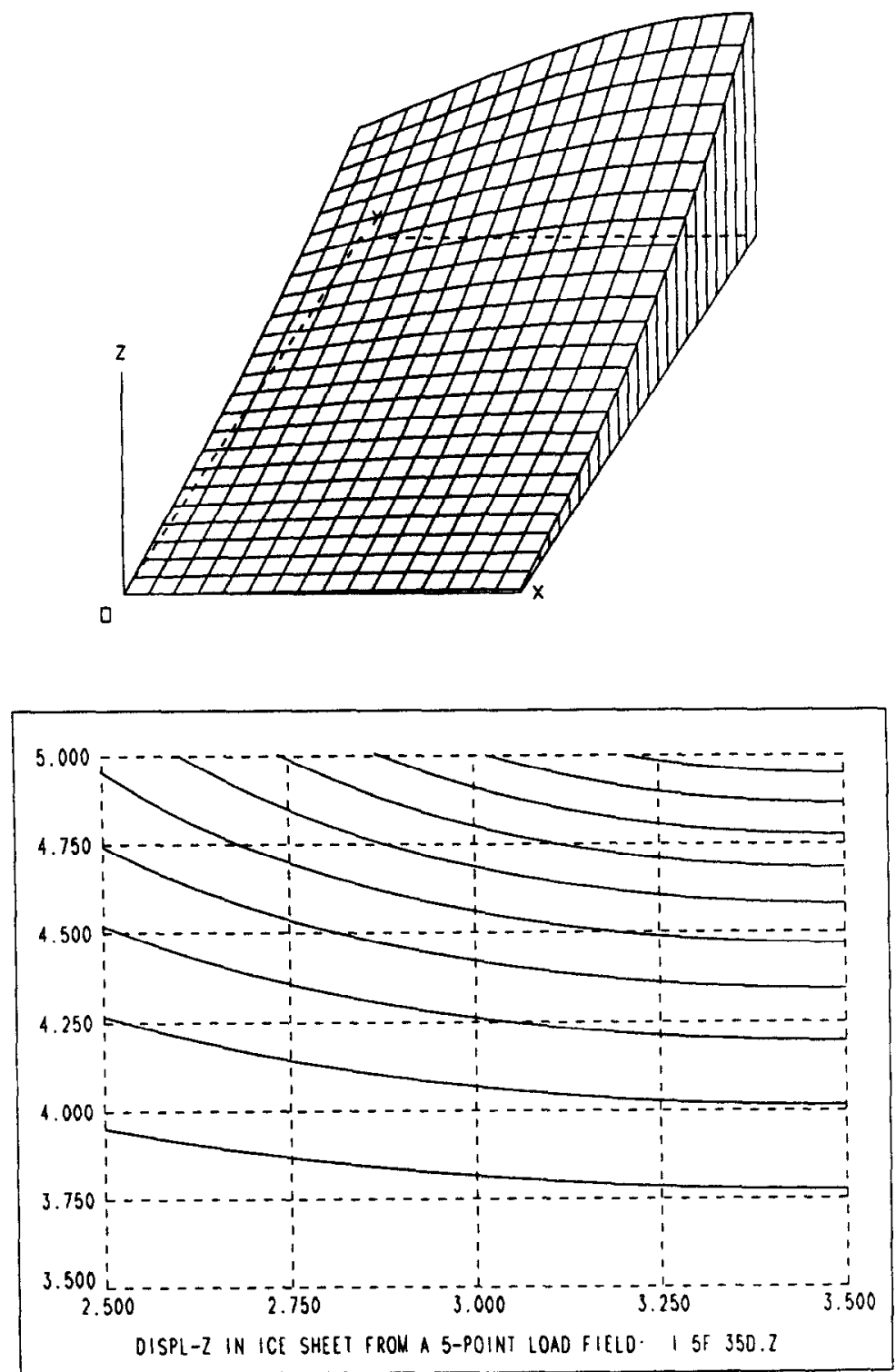

Fig. 11. Z-displacement in contour and in relief enlarged (II.5). 
stresses in the $x$-direction were dominant because of large bending moments in the ice sheet, whereas away from the structure, the axial stresses in the $x$-direction were more prominent.

3. It was noticed that bending moments $M_{x x}$ and $M_{y y}$ were of equal magnitude and importance throughout.

4. Near the offshore structure the stresses in the $x$ and $y$-directions were positive (tension) on the lower surface. Since ice is weak in tension and the surface is more rugged at the lower face this will help initiate cracks faster.

5. The presence of radial precuts made the ice sheet deflect more, see Figs 6-8, and caused larger stresses.

6. The assumption of uniform edge pressure on the ice-sheet due to contact with the inclined plane
Table 3

\begin{tabular}{lccc}
\hline Model & Displ. (m) & \multicolumn{2}{c}{ Max. stresses (kPa) } \\
No. & $\mathrm{B}_{z}$ & $\sigma_{x x}$ & $\sigma_{y y}$ \\
\hline II.2C & 0.02 & -195 & -278 \\
II.2CG & 0.02 & -180 & -251 \\
II.2CN & 0.02 & -67 & -113 \\
\hline
\end{tabular}

structure was not justified, for nodal point $A$ lifted off the incline, as seen in Table 1, model I1.2.

7. The most highly stressed elements were those in contact with the offishore structure and the precut. The plastic region of model II. $2 \mathrm{CN}$ was confined to three of these elements. A comparison of the maximum stresses in model $\mathbf{I I . 2}$ for linear, for geometrically nonlinear, and for geometrically and materially nonlinear is given in Table 3.
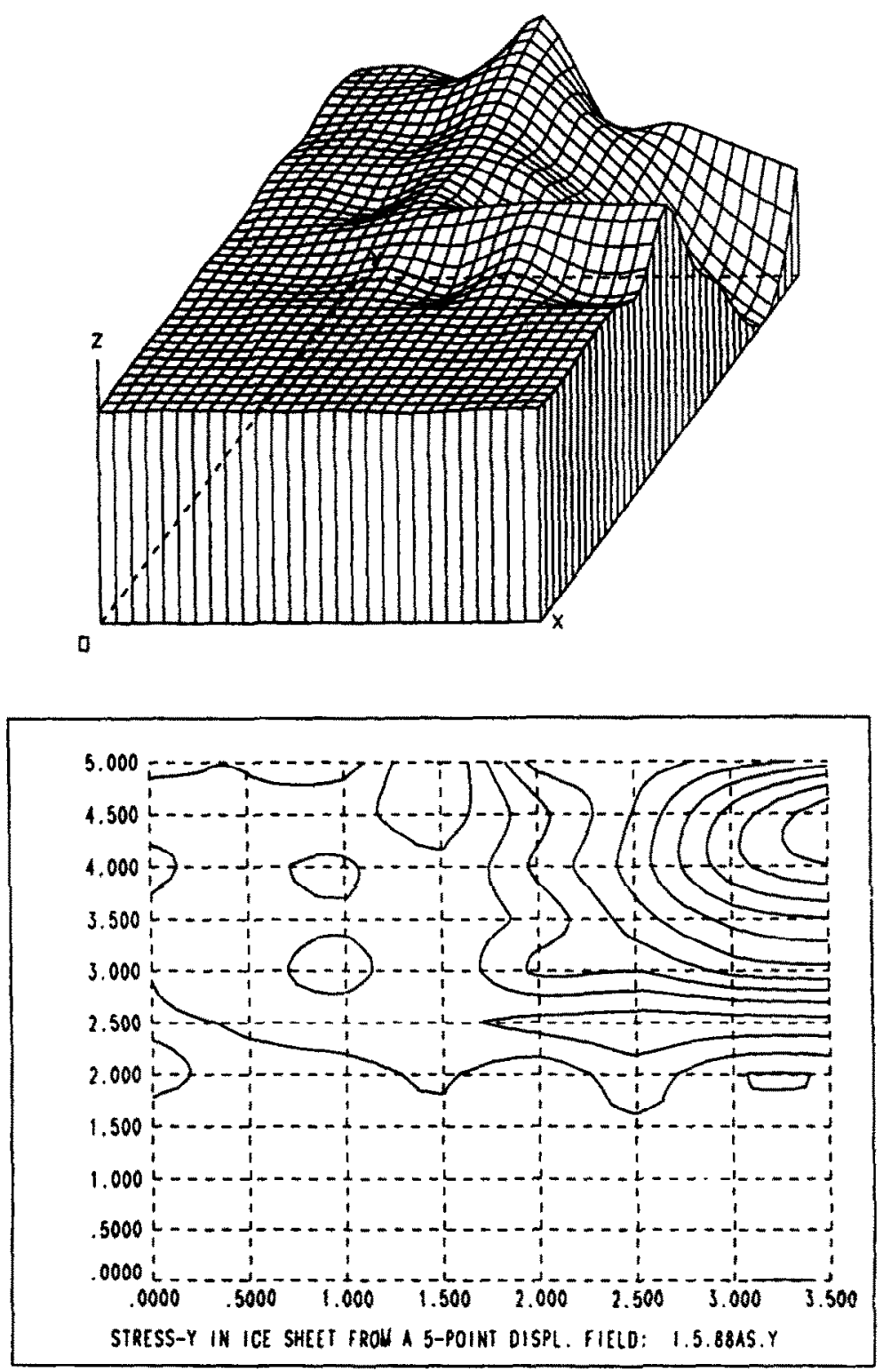

Fig. 12. Y-Stress in contour and in relief (II.5). 


\section{SOME CONCLUDING REMARKS}

1. This study has shown that the finite element technique is indeed a very useful and powerful tool to study ice/structure interaction.

2. Ice/structure interaction is a boundary displacement (contact) rather than a boundary (edge) load problem. Series II models address this for four different geometry conditions. Model II.S approximates a conical structure surface.

3. Use of post processors to display results graphically is very important. Otherwise most of the results are passed by unnoticed, see Figs 10-12.

4. This has been essentially a preliminary study; further study with nonlinear geometry and material properties are planned for the Series II ADINA model.

5. Radial precuts using hot water jets, mechanical ditchers such as Ditch Witch [8], or some other mechanical device, placed at strategic locations look very promising and need to be studied further even before the present oil glut is over!

Acknowledgement-I would like to thank Hsin-Chung Ho for Fig. 3 and a number of observations from his individual study report Course NA 511 .

\section{REFERENCES}

1. R. M. W. Frederking and G. W. Timco, Quantitative analysis of ice sheet failure against an inclined plane. Proc. 4th International Offshore Mechanics and Arctic Engineering Symposium, ASME, Dallas, pp. 160-169 (1985).

2. K. R. Croasdale, Ice forces on fixed, rigid structures. In CRREL Sp. Rep. 80-26, pp. 34-106, Hanover, NH, U.S.A. (1980).

3. T. D. Ralston, Ice force design considerations for conical off-shore structures. Proceedings 4th International Conference on Port and Ocean Engineering under Arctic Conditions, St. John's, Newfoundland, pp. 741-752 (1978).

4. C. Sorensen, Interaction between floating ice sheets and sloping structures. Institute of Hydrodynamics and Hydraulic Engineering, Technical University of Denmark, Series Paper No. 19 (1978).

5. G. W. Timco, Model tests of ice forces on a wide inclined structure. Proc. IAHR Symposium on Ice, Hamburg, Vol. 2, pp. 87-96 (1984).
6. P. Tryde, Intermittent ice forces acting on inclined wedges. Report 77-16 U.S. Army, Cold Regions Research and Engineering Laboratory, Hanover, NH (1977).

7. R. Abdelnour, Model tests of an icebreaking inclined piane. Report No. FR 289C-2, Actec Canada Limited, Ottawa (1979).

8. V. Manikian and G. N. McDonald, Method for weakening the ice cover in northern rivers. Civil Engineering in the Arctic Offshore, Proceedings of the Conference Arctic 85, ASCE San Francisco, CA, March 1985.

9. K.-J. Bathe, E. L. Wilson and F. E. Peterson, SAP IV A structural analysis program for static and dynamic response of linear systems. Report EERC-73-11, College of Engineering. University of California, Berkeley, CA, April 1974.

10. K.-J. Bathe, ADINA A finite element program for automatic dynamic incremental nonlinear analysis. Report 82448-1, MIT, Cambridge, MA, December 1978.

\section{FURTHER READING}

E. Enkvist, On the ice resistance encountered by ships operating in the continuous mode of ice-breaking. Report No. 24, The Swedish Academy of Engineering Sciences in Finland, Helsinki: Keskuskirjapaino Oy (1972).

A. D. Kerr, The bearing capacity of floating ice plates subjected to static or quasi-static loads. Research Report 333, U.S. Army Cold Regions Research and Engineering Laboratory, Hanover, NH (1975).

M. P. Langleben and E. R. Pounder, Elastic parameters of sea ice. In Ice and Snow Properties, Processes, and Applications (Edited by W. D. Kingerly), pp. 619-78. MIT Press, Cambridge, MA (1963).

V. R. Milano, Ship resistance to continuous motion in ice. In Transactions (of the Society of Naval Architects and Marine Engineers), Vol. 81, pp. 274-306. The Society of Naval Architects and Marine Engineers, New York (1973).

J. N. Naegle, Ice-resistance prediction and motion simulation for ships operating in the continuous mode of icebreaking. Ph.D. dissertation, The University of Michigan (1980).

D. E. Nevel, A semi-infinite plate on an elastic foundation. Research Report 136, U.S. Army Cold Regions Research and Engineering Laboratory, Hanover, NH (1965).

G. P. Vance, A modeling system for vessels in ice. Ph.D. dissertation, The University of Rhode Island (1974).

W. Weeks and A. Assur, The mechanical properties of sea ice. U.S. Army Cold Regions Research and Engineering Laboratory, Hanover, NH (1967). 